\title{
Cost of Treatment of Cerebral Aneurysm Embolization: Study of Associated Factors
}

\author{
Amine Cheikh - Razine Rachid - Aasfara Jehanne - Ababou Adil · \\ Benomar Ali · Yahya Cherrah · El Hassani Amine · El Quessar Abdeljalil
}

Received: April 11, 2016 / Published online: June 9, 2016

(C) The Author(s) 2016. This article is published with open access at Springerlink.com

\section{ABSTRACT}

Background: Surgical

clipping

or

endovascular coiling are the main procedures used in the treatment of cerebral aneurysms, with a preference for endovascular coiling. In Morocco, the

Enhanced content To view enhanced content for this article go to http://www.medengine.com/Redeem/ E3D4F0604D2C38C2.

A. Cheikh $(\bowtie) \cdot$ B. Ali

Faculty of Medicine, Abulcasis University, Rabat, Morocco

e-mail: Cheikh.amine@gmail.com

A. Cheikh · Y. Cherrah

Team of Pharmacoepidemiology and Pharmacoeconomics, Faculty of Medicine and Pharmacy, Mohammed V University, Rabat, Morocco

A. Cheikh

Department of Pharmacy, Cheikh Zaid Hospital, Rabat, Morocco

R. Rachid

Department of Public Health, Faculty of Medicine and Pharmacy, Mohammed V University, Rabat, Morocco

\section{A. Jehanne $\cdot$ B. Ali}

Neurogenetics Research Team, Faculty of Medicine and Pharmacy, Mohammed V University, Rabat, Morocco number of patients needing endovascular coiling is growing, but many of them do not have access to this technique. The aim of this study was to determine the main parameters associated with variations in the total cost of this procedure in order to establish the amount (lump sum) that may be reimbursed by health insurance funds.

Methods: One hundred and seventeen patients with 124 aneurysms were admitted for treatment of one or more intracranial

A. Adil

Department of Intensive Care, Cheikh Zaid

Hospital, Rabat, Morocco

\section{E. H. Amine}

Department of Pediatrics, Faculty of Medicine and

Pharmacy, Mohammed V University, Rabat,

Morocco

E. H. Amine

Cheikh Zaid Hospital, Rabat, Morocco

E. Q. Abdeljalil

Department of Neuroradiology, Cheikh Zaid

Hospital, Rabat, Morocco 
aneurysms between January 2010 and December 2015. The overall cost of hospitalization was assessed by using the micro-costing technique. The calculation was based on the tariffs of medical procedures as defined by the Ministry of Health in Morocco. A regression analysis was used to define the correlation between the overall cost and the various parameters.

Results: Univariate linear regression showed that the total cost was influenced by overall duration of hospitalization, ICU duration of hospitalization and size of aneurysm. On the other hand, univariate linear regression showed that the total cost was not influenced by sex, localization of aneurysm, and size of the aneurysm's neck. However, multivariate linear regression showed that the total cost was influenced by one type of insurance health, overall duration of hospitalization, ICU duration of hospitalization, size of the aneurysm, and size of the aneurysm's neck.

Conclusion: Setting a rate for reimbursement of patients who have had coiling treatment for a cerebral aneurysm should take into account the results of our study in order to limit the costs borne by patients. The parameters that influence the overall cost must be reimbursed in each case while the parameters that do not influence treatment costs could be included in a lump sum.

Keywords: Aneurysm embolization; Endovascular coil; Health insurance; Micro-costing; Reimbursement

\section{BACKGROUND}

Aneurysmal subarachnoid hemorrhage (aSAH) is a significant cause of morbidity and mortality throughout the world [1]. Aneurismal rupture, accompanied by a SAH, is associated with a mortality of $30-67 \%$ and a morbidity of $15-30 \%$ $[2,3]$. The overall prevalence of intracranial aneurysm is between $0.5 \%$ and $6 \%$ of the total population, based on angiographic study or autopsy $[4,5]$. These account for about $80-85 \%$ of non-traumatic subarachnoid hemorrhages [6]. There are two options for treating cerebral aneurysms, neurosurgical treatment with clipping of the malformation and neuroradiology treatment (embolization) to occlude the malformation via an endovascular procedure. The proportion of patients treated with microsurgery has decreased in the last two decades, especially in the elderly in whom embolization should strongly be considered as a first-line treatment for cerebral aneurysms [7]. This phenomenon has increased since the publication of the International Subarachnoid Aneurysm Trial (ISAT) study in 2002 [8].

The ISAT is the first multicenter prospective randomized trial comparing endovascular treatment and surgery [8]. A total of 2,143 patients with ruptured intracranial aneurysms were randomly assigned to clipping $(n=1070)$ or coiling $(n=1073)$. The ISAT trial demonstrated that in patients with ruptured intracranial aneurysms suitable for both treatments, endovascular coiling is more likely to result in independent survival at 1 year than neurosurgical clipping; this survival benefit continues for at least 7 years. The risk of late rebleeding is low, but is more common after endovascular coiling than after neurosurgical clipping [9].

New and innovative procedures, such as cerebral aneurysm coiling, can be associated with significant cost and will be in the spotlight in this changing landscape [10]. The average cost of endovascular treatment differs from one country to another. In the USA, two studies were conducted on a predictive model of the 
cost of hospitalization after cerebral aneurysm coiling and cerebral aneurysm clipping $[10,11]$. They concluded that the median hospitalization cost was US\$35,446 (31,192€) and US\$69,304 $(60,988 €)$ for unruptured and ruptured aneurysms, respectively, after cerebral aneurysm coiling [10]. In France, it was assessed as $14,477.39 €$ [12]. In Pakistan, the average cost of endovascular treatment was estimated at $€$ 5080 [13].

In our hospital, the overall average cost of treatment using the embolization technique was assessed to be $9697.8 € 14$; a large proportion of this amount is paid by the patients because the fee paid by Mandatory Health Insurance regimen is only $5364 €$. Currently, the fee paid by the health insurance funds is the same whatever the clinical parameters of the patients (number of aneurysm, aneurysm size, size of the aneurysm neck, number of hospital days, number of devices used, etc.).

No study to date in Morocco has explored the clinical parameters associated with the change in cost of treatment of cerebral aneurysms by embolization. Such a study could be used to redefine the lump sum refunded by health insurance and minimize the fees paid by patients. This co-payment can be catastrophic in certain situations.

Our aim was to study the parameters that influence the overall cost of treatment of cerebral aneurysm embolization care in order to take them into account in the definition of the lump sum to be reimbursed for this technique by health insurance funds.

\section{METHODS}

One hundred and seventeen patients who underwent endovascular treatment of one or more intracranial aneurysms were followed between January 2010 and October 2015. The cost was assessed by using the micro-costing method that takes into account all direct costs (hospitalization, physician services, visits, clinical investigations, and medications). The total cost was estimated by adding up the money spent by patients for treatment modality. The costs of different services were collected from the hospital billing system. It included data on all expenses incurred by patients during hospitalization. All costs are presented in Euros ( 1 Euro $=11$ Moroccan Dirhams (MAD)). The cost of treatment reported in this article does not include expenditure on additional hospitalization in another institution after discharge, rehabilitation in any institution other than Cheikh Zaid Hospital, or any anticipated expenditure regarding future procedures.

The parameters that could influence the overall cost of care for the treatment of intracranial aneurysm by embolization and that we studied were: Age, sex, type of insurance health coverage, origin, time between hospital admission and the onset of symptoms, overall length of stay, intensive care unit (ICU) length of stay, admission pattern, glasgow coma scale score, localization of the aneurysm, number of the aneurysm, size of the aneurysm, and size of the aneurysm's neck.

Statistical analyses were performed using SPSS 13.0 for Microsoft Windows XP software. Distributed continuous variables were expressed as means \pm standard deviations or as median and interquartile ranges. Qualitative variables were expressed as number and frequencies. The correlation between cost and other qualitative and quantitative parameters was established with the Spearman and Mann-Whitney tests. The Kruskal-Wallis test was used for comparing 
between-group costs. The variables associated with the cost were studied by univariate and multivariate linear regression. The variables that were associated statistically significantly with costs or had a $p$ value less than 0.3 in the univariate analysis were used in the multivariate analysis. The level of significance was fixed at $5 \%$.

This article does not contain any new studies on human or animal subjects performed by any of the authors.

\section{RESULTS}

A description of the clinical parameters of the patients in our study is presented in Table 1 below.

In total, 124 aneurysms in 117 patients were treated. The mean age of the patients was $51.2 \pm 14$ years. Fifty-one $(43.6 \%)$ patients were men and 66 (56.4\%) were women. The sex ratio was $\mathrm{M} / \mathrm{F}=0.43$. Seventy $(60 \%)$ patients were covered by health insurance. The median overall stay was 7 days (range 4-11), 1 day in the ICU (1-2) and 5 days in medical units (2.5-9).

The overall average cost of treatment was $9606.0 €$, varying from $3,702.3 €$ to $32,172.3 €$. Pharmaceutical products represent $55 \%$ of the overall cost $(70 \%$ for medical devices and $30 \%$ for drugs) and the average was $5280.5 €$ with a range of $2087.4 €-19,526.2 €$.

Univariate linear regression showed that the total cost was influenced by overall duration of hospitalization, ICU duration of hospitalization, size of aneurysm. On the other hand, univariate linear regression showed that the total cost was not influenced by sex, localization of the aneurysm, and size of aneurysm's neck (Table 2).

However, multivariate linear regression showed that the total cost was influenced by
Table 1 Clinical parameters of 117 patients treated by embolization

Patient characteristics

Number

(\%)

Health insurance

National Fund for public salaries

$40(34.2)$

(CNOPS)

National Fund for private salaries (CNSS) 4 (3.4)

Out of pocket

$47(40.2)$

Private fund for private salaries

$26(22.2)$

Tobacco

Yes

No

$79(67.5)$

Arterial hypertension

Yes

28 (23.9)

No

89 (76.1)

Admission causes

Sub-arachnoid hemorrhage

$91(77.8)$

Ophthalmological disorders

13 (11.1)

Recovery (recanalization)

$7(6.0)$

Fortuitous

$4(3.4)$

Iatrogenic

2 (1.7)

Distance from the hospital

$\begin{array}{ll}\text { Radius } \leq 100 \mathrm{~km} & 45(38.5) \\ 100 \mathrm{~km}<\text { radius } \leq 200 \mathrm{~km} & 16(13.7) \\ \text { Radius }>200 \mathrm{~km} & 26(22.2) \\ \text { Foreigners } & 15(12.8) \\ \text { Undefined } & 15(12.8)\end{array}$

Admission after symptoms

Less than $48 \mathrm{~h}$

$24(20.5)$

Between $48 \mathrm{~h}$ and 7 days

$28(23.9)$

Between 7 and 30 days

$30(25.6)$

Over 30 days

7 (6.0)

Recovery

$9(7.7)$

Imprecise

19 (16.3) 
Table 1 continued

\begin{tabular}{|c|c|}
\hline Patient characteristics & $\begin{array}{l}\text { Number } \\
(\%)\end{array}$ \\
\hline \multicolumn{2}{|l|}{ Location } \\
\hline Anterior communicating & $40(34.2)$ \\
\hline Middle cerebral artery & $11(9.4)$ \\
\hline Para-ophthalmic & $14(12.0)$ \\
\hline Intracranial carotid bifurcation & $16(13.7)$ \\
\hline Posterior communicating & $16(13.7)$ \\
\hline Posterior circulation & $11(9.4)$ \\
\hline Intracavernous & $7(6.0)$ \\
\hline Other location & $2(1.7)$ \\
\hline \multicolumn{2}{|l|}{ WFNS grading scale } \\
\hline I & $86(73.5)$ \\
\hline II & $14(12.0)$ \\
\hline III & $7(6.0)$ \\
\hline IV & $10(8.5)$ \\
\hline \multicolumn{2}{|l|}{ Number of aneurysms } \\
\hline 1 & $111(94.9)$ \\
\hline 2 & $5(4.2)$ \\
\hline 3 & $1(0.9)$ \\
\hline \multicolumn{2}{|l|}{ Ruptured or unruptured } \\
\hline Yes & $91(77.8)$ \\
\hline No & $26(22.2)$ \\
\hline
\end{tabular}

WFNS World Federation of Neurosurgical Societies

one type of health insurance, overall duration of hospitalization, ICU duration of hospitalization, size of aneurysm, and size of the aneurysm's neck (Table 2).

\section{DISCUSSION}

Our sample is considered one of two large series of intracranial aneurysm treatments using embolization in Morocco. This series is the only series that has been published and that sets out all expenses related to the care of patients within the hospital. This was achieved with the availability of an integrated hospital information system that reports all expenses related to patient care.

Almost all the studies published have compared the cost of coiling and clipping of ruptured intracranial aneurysms. All these studies originate from developed countries where medical insurance covers most of the medical expenses, and where the per capita income is higher than the world average [15]. They concluded that while the endovascular procedure tended to be more expensive in terms of cost of consumables, this expense was more than compensated by savings in staffing costs, and the period and cost of hospitalization [13, 16-19].

Johnston et al. concluded that total length of stay was longer (mean 7 days for surgical patients vs. 5 days for endovascular patients) and hospital charges were greater for surgical clipping (US\$ 38,000 for surgical patients vs. US $\$ 33,400$ for endovascular patients) [20]. Duan et al. (Cleveland, OH, USA) concluded that morbidity and length of stay for patients treated with clipping was greater. Total hospital costs and variable direct costs for clipping were significantly lower than for coiling ( $p=0.003$, $p<0.001$, respectively). Fixed direct costs and fixed indirect costs for clipping were higher than for coiling ( $p<0.001, p<0.001$, respectively). Variable direct costs comprised $50.5 \%$ and 68.6 $\%$ of total hospital costs for clipping and coiling, respectively $(p<0.001)$ [21].

Lad et al., however, concluded that although the surgical clipping resulted in lower reoperation rates, it was associated with higher complication rates and initial costs. However, overall costs at 2 and 5 years were similar to endovascular coiling due to the significantly higher number of follow-up angiograms and outpatient costs in these patients [22]. 
Table 2 Parameters related to changes in overall cost of treatment of cerebral aneurysm embolization: Univariate and multivariate analysis (linear regression)

\begin{tabular}{|c|c|c|c|c|c|c|}
\hline \multirow[t]{2}{*}{ Independent variables } & \multicolumn{3}{|c|}{ Univariate analysis } & \multicolumn{3}{|c|}{ Multivariate analysis } \\
\hline & $\bar{\beta}$ & $95 \% \mathrm{CI}$ & $p$ & $\bar{\beta}$ & $95 \% \mathrm{CI}$ & $p$ value \\
\hline \multicolumn{7}{|l|}{ Sex } \\
\hline Male & 0 & & & 0 & & \\
\hline Female & $1,921.0$ & -238.4 to $4,080.5$ & 0.08 & $1,058.6$ & -106.1 to $2,223.3$ & 0.07 \\
\hline \multicolumn{7}{|l|}{ Health insurance type } \\
\hline $\begin{array}{l}\text { National Fund for } \\
\text { public salaries (CNOPS) }\end{array}$ & 0 & & & 0 & & \\
\hline $\begin{array}{l}\text { National Fund for private } \\
\text { salaries (CNSS) }\end{array}$ & -2916.8 & $-5,771.4$ to 62.1 & 0.04 & -516.9 & $2,026.6-992.8$ & 0.5 \\
\hline Out of pocket & -491.9 & $-6,213.8$ to 5230.1 & 0.86 & 3744.3 & $665.4-6,823.1$ & 0.01 \\
\hline Private fund for private salaries & -3821.9 & $-6,457.2$ to $1,186.7$ & 0.04 & -700.4 & $-2,160.4$ to -759.6 & 0.34 \\
\hline \multicolumn{7}{|l|}{ Location of aneurysm } \\
\hline Anterior communicating & 0 & & & 0 & & \\
\hline Middle cerebral artery & -4965.3 & $-12,903.9$ to $2,973.2$ & 0.22 & 2703.8 & $-1,393.5$ to $6,801.1$ & 0.19 \\
\hline Para-ophthalmic & -4244.5 & $-12,516.3$ to $4,027.2$ & 0.31 & 1857.2 & $-2,331.3$ to $6,045.7$ & 0.38 \\
\hline Intracranial carotid bifurcation & -4622.4 & $-13,098.4$ to $3,853.6$ & 0.28 & 3279.4 & $-1,071.9$ to $7,630.8$ & 0.14 \\
\hline Posterior communicating & -4116.2 & $-12,592.3$ to $4,359.8$ & 0.34 & 2740.8 & $-1,565.5$ to $7,046.7$ & 0.21 \\
\hline Posterior circulation & -4386.9 & $-12,624.2$ to $3,850.3$ & 0.30 & 2762.4 & $-1,455.3$ to $6,980.0$ & 0.19 \\
\hline Intracavernous & -5291.1 & $-13,702.7$ to $3,120.5$ & 0.22 & 1622.6 & $-2,727.9$ to $5,973.2$ & 0.46 \\
\hline Other location & -7584.7 & $-17,061.2$ to $1,891.8$ & 0.12 & -584.0 & $-5,519.9$ to $4,351.8$ & 0.81 \\
\hline Overall length of stay & 363.3 & $283.6-4,43.1$ & $<0.001$ & 90.0 & $15.9-164.2$ & 0.01 \\
\hline ICU length of stay & 560.9 & $476.1-645.8$ & $<0.001$ & 497.5 & $398.9-596.0$ & $<0.001$ \\
\hline Size of aneurysm & 246.7 & $43.6-449.9$ & 0.017 & 211.4 & $58.3-364.4$ & 0.007 \\
\hline Size of aneurysm's neck & 426.0 & -38.2 to 890.2 & 0.07 & 388.2 & $34.0-742.4$ & 0.03 \\
\hline
\end{tabular}

CNOPS Caisse Nationale des Organismes de Prévoyance Sociale, CNSS Caisse Nationale de Sécurité Sociale, ICU intensive care unit

Similarly, some observational studies of patients with unruptured intracranial aneurysms show that discharge outcomes were better and hospital costs were lower after endovascular treatment than after surgery. These patients showed no difference between the two treatments in 1-year outcomes and later rebleeding, although few data were available for this comparison $[19,23]$.

We performed this comparative study at Cheikh Zaid hospital in Rabat and we found similar results compared to the studies cited above. Ninety patients were treated by embolization and 13 patients by neurosurgery. 
The median overall length of stay was greater in patients treated by neurosurgery (13 vs. 8 days, respectively). By contrast, the median cost of pharmaceutical products was more signifcant for embolization than for neurosurgery $(4,000 €$ vs. $1,570 €$, respectively). This difference was offset by the cost of hospitalization which was far more for patients treated with neurosurgery. The difference in the average overall cost between the two groups was not significant $(p=0.39)$.

Furthermore, endovascular treatment can be a good option for the treatment of cerebral aneurysms in this context; it reduces the length of hospital stay, and therefore avoids the risk of complications or nosocomial infections. This will also allow the hospital to admit more patients. However, the high cost of pharmaceutical products used in such a procedure can impact heavily on the budget of the hospital.

Our series concluded that the cost of pharmaceutical products is one of the major handicaps of the development of this technique (the share of pharmaceutical product cost is $55 \%$ of the overall cost), specifically coils, stents, balloons, micro-catheters, and guides. In Morocco, there is no regulation (pricing) of medical devices by the ministry of health [14]. The cost of medical devices is negotiated between hospitals and suppliers after validation by the committee on drugs and medical devices [14]. This is one of the factors contributing to the high cost of medical devices used in this technique. The fact that the cost of coils and other medical devices is the main contributor to the higher costs of coiling was also found in the study by Duan et al. [21].

The second obstacle in improving this technique is the balance of fees paid by health insurance $(5364 €)$, which is only $75 \%$ of the average full cost calculated in this series. The remaining cost is borne by the patients. Unfortunately, the lump sum as defined in public hospitals and health insurance funds is not always reimbursed by these funds. Moreover, there is no agreement between health insurance funds and the private sector to support all expenses related to this procedure.

This study shows that the lump sum paid or reimbursed by the health insurance system remains very low and does not encourage health professionals and patients to use this technique as much as possible. Health insurance aims to improve patient access to quality care while minimizing their contribution and avoiding situations where they may be faced with catastrophic expenses. In the case of treatment with embolization, the health insurance system has a strong interest in encouraging use of this technique with minimal charges for patients, by increasing the fees allocated to this procedure to cover all expenses especially pharmaceutical products, which account for $55 \%$ of the overall cost. Therefore, to develop this technique in Morocco, we suggest valuing the cost of the technique and reducing co-payments incurred by patients.

The results of our study show that it is very difficult to allocate a lump sum to this treatment because the overall cost of care depends on several parameters that cannot be standardized between patients. The results of our study also show that the overall cost of care is influenced by the total length of stay in hospital and the length of stay in the ICU. This result can be explained by the fact that if the number of patient days increased, specifically in the ICU, the overall cost of hospitalization becomes important and significantly affects the cost of global support. 
In addition, there is a significant correlation between the global cost and the size of the aneurysm on the one hand and the size of the aneurysm's neck on the other. These results are logical because the larger the size of the aneurysm, the greater the number of coils. Also, the number and type of devices used are related to the aneurysm's neck size; the neuroradiologist is forced to use a balloon dilatation or stent, which involves a significant increase in costs incurred.

Our study has some limitations, mainly relating to the lack of data on the cost of other services that the patient may have outside the hospital, the cost of other services provided post-embolization, and the amount actually reimbursed by the health funds for each patient.

\section{CONCLUSION}

The coiling technique is an effective modality for the treatment of intracranial aneurysms. Unfortunately, this technique is expensive and not available to all patients, especially those not covered by a health insurance plan. In addition, the co-payment that patients covered by the compulsory health insurance scheme in Morocco have to bear is significant, as the package specified by the national health insurance agency and insurance funds remains below the actual value of the disease management.

Setting a rate for reimbursement of patients who have had coiling treatment of a cerebral aneurysm should take into account the results of our work in order to limit the amount borne by patients. The parameters that influence the overall cost must be reimbursed in each case while the parameters that do not influence treatment costs could be included in a package.

\section{ACKNOWLEDGMENTS}

No funding or sponsorship was received for this study or publication of this article. All authors had full access to all of the data in this study and take complete responsibility for the integrity of the data and accuracy of the data analysis. All named authors meet the International Committee of Medical Journal Editors (ICMJE) criteria for authorship for this manuscript, take responsibility for the integrity of the work as a whole, and have given final approval for the version published. A. Cheikh, A. Jehanne, A. Adil, E. -Q. Abdeljalil, and B. Ali designed data collection tools, monitored data collection for the whole trial, wrote the statistical analysis plan, cleaned and analyzed the data, and drafted and revised the paper. A. Cheikh, A. Adil, and R. Rachid analyzed the data and drafted and revised the paper. B. Ali, Y. Cherrah, E. -H. Amine, and E. -Q. Abdeljalil revised the draft paper. The authors wish to thank all the individuals and institutions that made this study possible, especially Dr Zakia Cheikh and Mr Anis Soulaymane.

Disclosures. A. Cheikh, R. Rachid, A. Jehanne, A. Adil, B. Ali, Y. Cherrah, E. -H. Amine and E. -Q. Abdeljalil declare no conflicts of interest.

Compliance with Ethics Guidelines. This article does not contain any new studies with human or animal subjects performed by any of the authors.

Open Access. This article is distributed under the terms of the Creative Commons Attribution-NonCommercial 4.0 International License (http://creativecommons.org/licenses/ by-nc/4.0/), which permits any noncommercial use, distribution, and reproduction in any 
medium, provided you give appropriate credit to the original author(s) and the source, provide a link to the Creative Commons license, and indicate if changes were made.

\section{REFERENCES}

1. Connolly ES, Rabinstein AA, Carhuapoma JR, Derdeyn CP, Dion J, Higashida RT, Hoh BL, Kirkness CJ, Naidech AM, Ogilvy CS, Patel AB, Thompson BG, Vespa P. Guidelines for the management of aneurysmal subarachnoid hemorrhage: a guideline for healthcare professionals from the american heart association/ american stroke association. Stroke. 2012;43(6):1711-37.

2. King JT Jr, Berlin JA, Flamm ES. Morbidity and mortality from elective surgery for asymptomatic, unruptured, intracranial aneurysms: a meta-analysis. J Neurosurg. 1994;81:837-42.

3. Raaymakers TW, Rinkel GJ, Limburg M, Algra A. Mortality and morbidity of surgery for unruptured intracranial aneurysms: a meta-analysis. Stroke. 1998;29:1531-8.

4. Johnston SC, Higashida RT, Barrow DL, Caplan LR, Dion JE, Hademenos G, et al. Recommendations for the endovascular treatment of intracranial aneurysms: a statement for healthcare professionals from the Committee on Cerebrovascular Imaging of the American Heart Association Council on Cardiovascular Radiology. Stroke. 2002;33(10):2536-44.

5. Bardach NS, Zhao S, Gress DR, Lawton MT, Johnston SC. Association between subarachnoid hemorrhage outcomes and number of cases treated at California hospitals. Stroke. 2002;33(7):1851-6.

6. Kassell NF, Torner JC, Jane JA, Haley EC Jr, Adams HP. The International Cooperative Study on the Timing of Aneurysm. Surgery. Part 2: surgical results. J Neurosurg. 1990;73:37-47.

7. Smith MJ, Sanborn MR, Lewis DJ, Faught RW, Vakhshori V, Stein SC. Elderly patients with intracranial aneurysms have higher quality of life after coil embolization: a decisionanalysis. J Neurointerv Surg. 2014;. doi:10.1136/ neurintsurg-2014-011394.

8. Molyneux AJ, Kerr R, Stratton I, Sandercock P, Clarke M, Shrimpton J, et al. International Subarachnoid Aneurysm Trial (ISAT) of neurosurgical clipping versus endovascular coiling in 2143 patients with ruptured intracranial aneurysms: a randomised trial. Lancet. 2002;360(9342):1267-74.

9. Molyneux AJ, Kerr RSC, Yu LM, Clarke M, Sneade M, Yarnold JA, Sandercock P. International subarachnoid aneurysm trial (ISAT) of neurosurgical clipping versus endovascular coiling in 2143 patients with ruptured intracranial aneurysms: a randomised comparison of effects on survival, dependency, seizures, rebleeding, subgroups, and aneurysm occlusion. Lancet. 2005;366(9488):809-17.

10. Bekelis Kimon, Missios Symeon, Labropoulos Nicos. Cerebral aneurysm coiling: a predictive model of hospitalization cost. J NeuroIntervent Surg. 2015;7:543-8.

11. Bekelis K, Missios S, MacKenzie TA, Labropoulos N, Roberts DW. A predictive model of hospitalization cost after cerebral aneurysm clipping. J NeuroIntervent Surg. 2016;8(3):316-22. doi:10. 1136/neurintsurg-2014-011575.

12. Labalette $\mathrm{C}$, et al. Embolisations des anévrismes cérébraux: évolutions du financement et perspectives. J Radiol. 2010;91:895-900.

13. Tahir MZ, et al. Cost-effectiveness of clipping vs coiling of intracranial aneurysms after subarachnoid hemorrhage in a developing country-a prospective study. Surg Neurol. 2009;72:355-61.

14. Amine C, El Abbadi Najia IH, Adil A, Yahya C, Quessar Abdeljalil EL. The cost of management of intracranial aneurysm by embolization in Morocco: about 48 cases. Int $\mathrm{J}$ Pharm Pharm Sci. 2014;6(2):822-6.

15. Li MH, Chen SW, Li YD, et al. Prevalence of unruptured cerebral aneurysms in Chinese adults aged 35 to 75 years: a cross-sectional study. Ann Intern Med. 2013;159:514-21.

16. Bairstow P, Dodgson A, Linto J. Comparison of cost and outcome of endovascular and neurosurgical procedures in the treatment of intracranial aneurysms. Australas Radiol. 2002;46:249-51.

17. Ballet AC, Guerien J, Taboulet F. Neurosurgical and endovascular treatment of intra cranial aneurysms: a cost analysis of two different strategies at the university hospital of Bordeaux (France). Neurochirurgie. 2002;48:419-25.

18. Hoh BL, Chi Y-Y, Dermott MA, Lipori PJ, Lewis SB. The effect of coiling versus clipping of ruptured and unruptured cerebral aneurysms on length of stay, hospital cost, hospital reimbursement, and surgeon 
reimbursement at the University of Florida. Neurosurgery. 2009;64(4):614-9.

19. Javadpour M, Harsh J, Willinsky RA. Analysis of cost related to clinical and angiographic outcomes of aneurysm patients enrolled in ISAT in a North American setting. Neurosurgery. 2005;56(5): 886-94.

20. Johnston SC. Effect of endovascular services and hospital volume on cerebral aneurysm treatment outcomes. Stroke. 2000;31:111-7.

21. Duan Y, Blackham K, Nelson J, Selman W, Bambakidis N. Analysis of short-term total hospital costs and current primary cost drivers of coiling versus clipping for unruptured intracranial aneurysms. J Neurointerv Surg. 2015;7(8):614-8.

22. Lad SP, Babu R, Rhee MS, Franklin RL, Ugiliweneza B, Hodes J, Nimjee SM, Zomorodi AR, Smith TP, Friedman AH, Patil CG, Boakye M. Long-term economic impact of coiling vs clipping for unruptured intracranial aneurysms. Neurosurgery. 2013;72(6):1000-11.

23. Qureshi AI, Janardhan V, Hanel RA, Lanzino G. Comparison of endovascular and surgical treatments for intracranial aneurysms: an evidence-based review. Lancet Neurol. 2007;6(9): 816-25. 